\title{
Hydraulic Characterization of Porous Materials Using a Rainfall Simulator to Model Flows in Natural and Artificial Non- Saturated Materials
}

\author{
F. X. Masson, ${ }^{1}$ H. B. Lefer, ${ }^{1,2}$ C. Boulemia ${ }^{3}$ and H. Naji ${ }^{3,4}$ \\ ${ }^{1}$ Centre of Research and Development in Soil Science, Economy, Environment and Planning, Lille; ${ }^{2}$ Université du littoral côte d’opale, Dunkerque \\ and Université Lille Nord de France; ${ }^{3}$ Université d'Artois, Béthune; ${ }^{4}$ Université Lille Nord de France, Villeneuve d’Ascq.
}

\begin{abstract}
Cumulative runoff curves are created by applying constant rainfall of known intensity using a rain simulator. These curves allow us to determine, with good accuracy, the initial loss, the initial time of runoff, and the constant loss. The approach is to model infiltration in an unsaturated medium using a draining reservoir paradigm. Simulated rainfall is applied to a typical soil considered to be composed of two superimposed layers of different permeabilities. This approach enables us to represent the drainage porosity as a function of the constant loss and the initial runoff time, which are measured during the rain simulation. Thus it is possible to calculate the infiltrated volumes, the initial runoff times, and the runoff volumes which are induced by rains of different intensities. Four case studies are used to illustrate the application of our approach.
\end{abstract}

\section{Introduction}

Water transportation in the non-saturated zone of porous materials such as natural soils, artificial soils, and various surfaces and artificial materials is characterized in many fields of science and engineering. Examples are hydrological and hydraulic calculations (e.g. Singh et al. 2002), analysis of the transfer of soil solutes (Vogel et al. 2006; Deng et al. 2005), measurement of the impermeabity of ground covers, and optimisation of agricultural irrigation (Wöhling et al. 2007).

Mathematical modeling is often used to model flow processes in an unsaturated environment (Corradini et al. 1997; Gandolfi and Savi 2000; Simunek et al. 2003; Panday and Huyakorn 2004; Schwen et al. 2011). Infiltration models based on the Richards equation formalise the spatio-temporal variability of transfer from the surface to the saturated zone. The water infiltration dynamic depends on parameters tied both to system inputs (rain intensity and rain duration) and to the porous receptor material (infiltration capacity). Models that attempt to reproduce this dynamic either depend on an empirical approach to the functional relationships between these variables, or on an attempt to reproduce the physical processes of water transfer in the material under certain simplifying assumptions (Hingray et al. 2009).

Most recent developments consider infiltration and runoff in a single model (Furman 2008). This coupling suggests an approach to water flow management during rain events. It can quantitatively or qualitatively show the effects of infiltration and runoff on surface and groundwater bodies (Köhne et al. 2011).

Such approaches, ranging from simple to complex, present several sets of challenges. To differentiate approaches, we should distinguish the model parameterisations, consider the heterogeneity of porous environments, and identify the internal and external limits of systems of representation. Thus the evaluation of the hydrodynamic parameters that characterise the soil (such as content, or hydraulic conductivity influenced by drainage, whether it is measured by multiple pressure levels or by a long column) may vary in complexity (Lazrag 2012). The assessment herein is based on the use of reduced volume samples that have been slightly modified.

In most modeling approaches, the three-dimensional variability of the hydrodynamic characteristics of the soil (two horizontal, one vertical) can lead to a parametrisation that is very complex and error prone. To address this difficulty, one can resort to inverse modelling: the use of observed phenomena which explain parameter set choices can also determine them. It is generally thought preferable to choose from several possible sets of parameters, and to develop robustly optimized algorithms (Mertens 2004).

A frequently seen approach is to use parameters from average values, but these do not adequately reflect the spatial heterogeneity of the modeled soils. Many models are built to represent flows as being through a single soil layer. Other models integrate a variety of soils into two layers of differential

Masson, F. X., H. B. Lefer, C. Boulemia and H. Naji. 2017. A Hydraulic Characterization of Porous Materials Using a Rainfall Simulator to Model Flows in Natural and Artificial Non-Saturated Materials. Journal of Water Management Modeling 25:C429.

https://doi.org/10.14796/JWMM.C429 @ C CHI 2017. www.chijournal.org ISSN 2292-6062. 
permeability (Corradini 1997). The use of average values may not accurately represent the boundary conditions of the system, such as the interface between the water and the porous environment. There is no consensus concerning the proper mathematical formulation of boundary conditions at interfaces (Furman 2008). These are concerns for hydraulic and soil specialists, but they also indicate the uncertainty of parameterization in inverse modeling. Effective models require accurate specification of the variables used (Friedel 2005); however it is usually impossible to accurately describe all observable situations (Köhne et al. 2011). Therefore observable variables cannot always be adopted at the operational level (Corradini et al. 2011).

As an example, the difference between soil water content (or imbibition) and gravity fed water can be identified via the observed fluxes. But these flows may be constant flows from either the transition period, integrating soil humectation phenomena, or from the initial resistance to the infiltrating water such as air pressure in soil cavities, or soil wettability. It is difficult to determine the extent to which these phenomena influence water flux.

Accurate measurement of multiple soil variables is difficult. To overcome this difficulty and to characterize the response of a porous unsaturated soil material to a rain event, we modeled the hydrodynamic behaviour of soil and some artificial materials using a rainfall simulator. The use of the simulator allows us to better analyse the volumes and the infiltrated flows through the soil materials, that is, the water content and the gravity fed water. This approach to soil function, mod-eled here as a heterogeneous environment composed of two layers having different permeability, leads to a straightforward interpretation of the obtained runoff curves, thereby closely approximating the hydrodynamic characteristics of the materials studied. Thereafter, the response of soils or artificial materials under different rainfall intensities can be computed. This model is illustrated by four case studies to show its usefulness.

The structure of this paper is as follows: the experimental setup, together with the relevant parameters and quantities needed to define it, are discussed in Section 2. Section 3 is devoted to the mathematical formulation and modeling of the problem being considered. Related issues are described and the model is supplemented with appropriate equations. The effects of simulated rainfall on soil behaviour are described and discussed in Section 4. The estimation of the hydrodynamic characteristics of the soil together with a discussion of them are presented in Section 5. Finally, Section 6 summarizes our findings and presents our conclusions.

\section{Rainfall Simulation}

Field rainfall simulation is often used to study the impact of rainfall on soil surfaces (such as the creation of a slaked crust or loss of permeability; e.g. Neave and Rayburg 2007), to measure the risk of soil erosion (Hamed et al. 2002; Martin et al. 2010; Roose et al. 2012), and to measure runoff (e.g. Perez-Latorre et al. 2010; Martinez-Murillo et al. 2013). Simulation devices (see Figure 1 below) may also simulate the hydraulic behaviour of the soil under the rainfall. The infiltrated water flows through the porous environment and, in the case of soil, through macropores $(\mu)$ consisting of things such as gaps among aggregates, old ducts made by roots, or tunnels left by underground fauna. These large porous volumes allow the gravity fed water to flow. Content water $\left(H_{r}\right)$ corresponds to the micro-porosity caused by the narrow gaps among the soil particles without allowing gravity-fed water to pass through. Note that $H_{r}$ can be determined based on laboratory tests or on equivalent humidity $\left(H_{e}\right)$. It should also be noted that numerous simulator models are available (e.g. Abudi et al. 2012; Iserloh 2013). Their principle remains the same: the device is adjusted to achieve a standard rainfall with an intensity $(I)$ and an energy close to those of a natural rainfall, on a land surface $(S)$, delimited by a frame that allows the collection of the runoff water $(R)$.

For this study, an ORSTOM-type simulator (Asseline et al. 1978; Asseline 1997) of height $3.5 \mathrm{~m}$ and intensity $33 \mathrm{~mm} / \mathrm{h}$, corresponding to a very intense rain event in Northern France, was used. Note that the energy of the raindrops on the ground is comparable to that of a natural rainfall (Salles et al. 2000). In addition, the watered surface area is $1 \mathrm{~m}^{2}$. The computed losses $(P)$ due to infiltration are divided into initial losses $\left(P_{i}\right)$ and continuing losses $\left(P_{c}\right)$. These denotations are those commonly understood by hydrologists and water engineers (Loveridge and Rahman 2013). Here, the intention is to measure the amount of infiltrated water that is retained by the material, the amount that is transferred to lower layers, and the runoff amount. These parameters are characteristics of the materials being studied. The primary goal is to simulate the response of soil subjected to a standard rainfall intensity of $33 \mathrm{~mm} / \mathrm{h}$ in order to characterize the behaviour of the porous material. It is assumed that, with respect to the rainfall, the runoff volume and the infiltration and transport of water through the soil are due to the properties of the soil material.

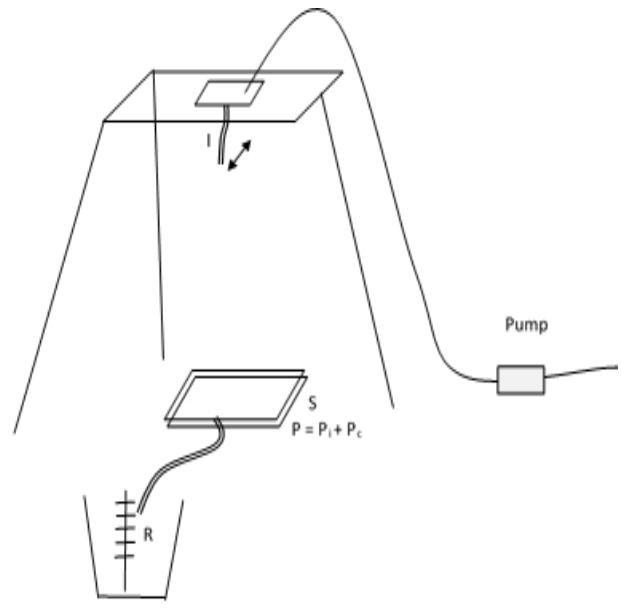

Figure 1 Outline schematic of a rain simulator (ORSTOM type). 


\section{Hydrodynamic Modeling of Soils}

It should be noted that water circulation or absorption in porous materials or soils depends on the characteristics of the materials in terms of porosity and permeability. Here, an operating model is implemented using a typical soil.

\subsection{Soil Settings}

It is well accepted that soils and porous materials are not isotropic. Thus the standard soil model adopted here is heterogeneous, and consists of two layers which are commonly encountered in nature. Figure 2 illustrates a soil with an upper level having a greater porosity than that of the lower level (Corradini et al. 2011). In other words, these levels have different permeabilities allowing faster transport through the higher level but also requiring greater storage in the upper part of the soil (level 1). For the sake of simplicity, it is supposed that all levels are homogeneous.

\begin{tabular}{c}
\hline level 1: Permeable bed \\
\hline level 2: Less permeable bed
\end{tabular}

Figure 2 Schematic illustration of two soil layers.

Note that this two-layer model approximates the surface level behavior, since the second layer of lower permeability will limit the flow through the upper layer and so induce the saturation of layer 1 when the rainfall amount is greater than the amount of runoff and the amount of gravity fed water that flows through the lower layer

By analogy, the behaviour of the level 1 soil is likened to a cracked reservoir (Figure 3 ) of height $H$, which is the maximum (full) water level; $h$ is the actual water level at time $t$, also referred to as the filling level, and $S$ denotes the reservoir surface area. Note that, for this model, the water overflow and leakage from the tank towards level 2 correspond to losses. Furthermore, it is assumed that the reservoir volume is filled on one hand with particles or aggregates, and on the other hand by pores (macropores) corresponding to the water volume contained in the reservoir that flows through the soil.

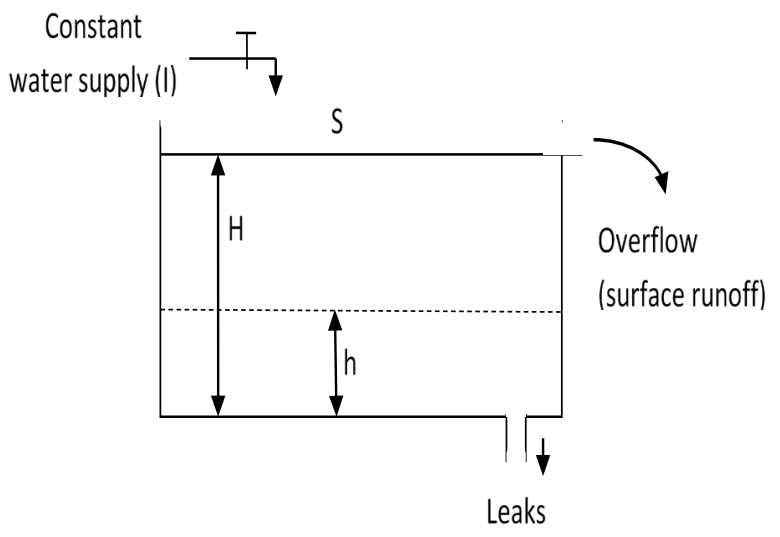

Figure 3 Reservoir with constant water supply and variable losses.

\subsection{Typical Soil Behaviour}

To investigate the soil behaviour, level 1 is assumed to be similar to the reservoir schematically shown in Figure 3. The water supply $(I)$ to the reservoir is provided by the rain. Note that initial losses are in total equal to the moisture content $\left(H_{r}\right)$, the filling of the macro-porosity drainage $(\mu)$, and variable losses $\left(P_{v}\right)$ to the lower level 2 as long as level 1 is not fully filled (see Figure 4). These losses vary with the load $h$, which itself is variable.

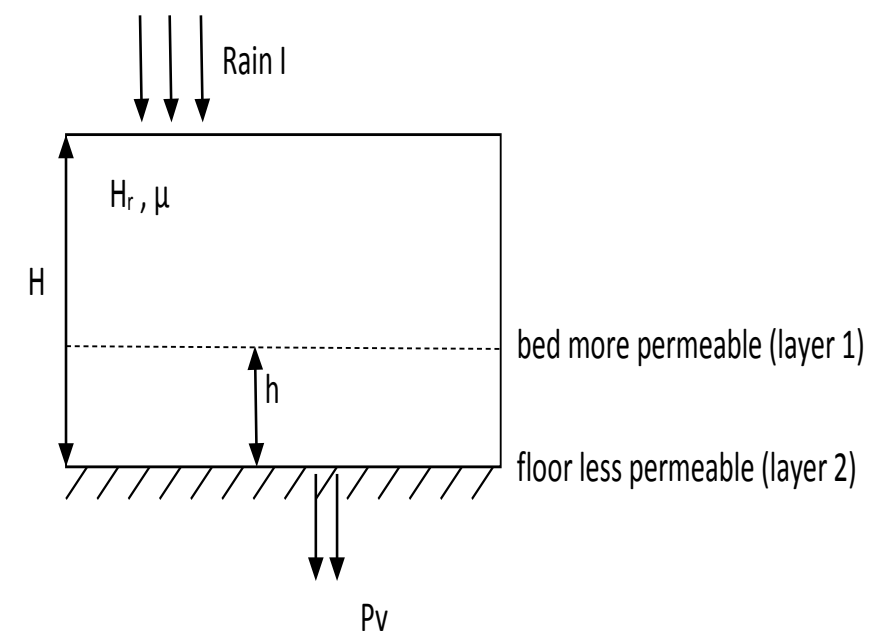

Figure 4 Soil functioning and loading in a temporary underground water table above a less permeable layer.

In the following, it is assumed that $H$ is the sum of pores (per unit of surface, $S$ ) representing the drainage porosity $(\mu)$, and disregarding aggregates or particles contained in the reservoir. Recall that variable losses $\left(P_{v}\right)$ are the losses before runoff, and the continuous losses $\left(P_{c}\right)$ are the water flow rate infiltrated for the steady state (corresponding to a maximum load). Likewise, the variable losses are equal to the continuous losses when $h$ is equal to $H$. Hence it can be stated that:

$$
\begin{aligned}
& P_{v}=0 \text { if } h=0 \text {, and } \\
& P_{v}<P_{c} \text { if } h<H .
\end{aligned}
$$

For a test rainfall, the initial loss value $\left(P_{i}\right)$, which is the amount of rainfall infiltrating the soil until the onset of runoff, is a function of the moisture content $\left(H_{r}\right)$, the drainage porosity of level $1(\mu)$, and of the volume of cumulative variable losses during the filling time of $\mu$ (i.e. $\Sigma P_{v}$ ):

$$
P_{i}=H_{r}+\mu+\sum P_{v}
$$

\subsection{Infiltration Dynamic Factors}

Assuming a perfect soil (i.e. one without superficial impediments affecting the infiltration and having a uniform porosity above level 2), Figure 5 shows the infiltration curve $\left(I^{\prime}\right)$ which has the same slope as the rainfall curve $(I)$. In the same figure, distribution of initial losses $\left(H_{r}\right),(\mu)$ and $\left(P_{v}\right)$ are also schematically depicted. 


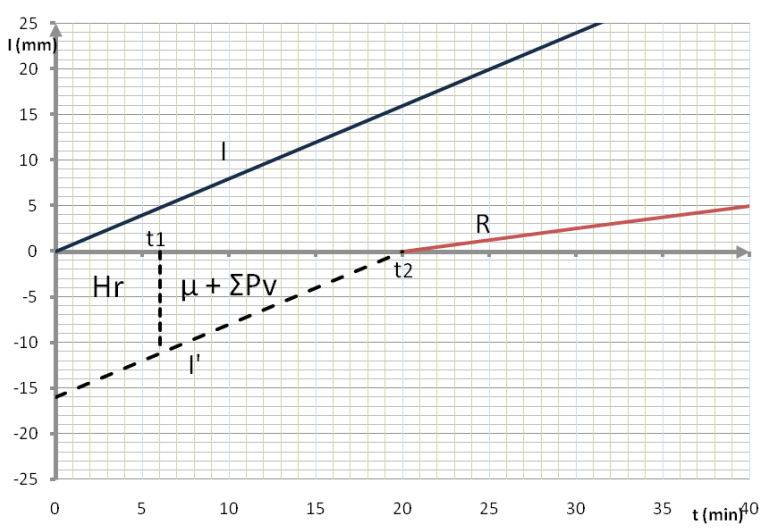

Figure 5 Representation of the infiltration $\left(I^{\prime}\right)$ and the runoff (R).

In Figure 5, the quantities shown are:

$I=$ rainfall $(\mathrm{mm} / \mathrm{h})$,

$l^{\prime}=$ infiltrated rain $(\mathrm{mm} / \mathrm{h})$,

$R=\operatorname{runoff}(\mathrm{mm} / \mathrm{h})$,

$H_{r}=$ soil moisture content (mm),

$\mu=$ drainage porosity (porosity corresponding togravity fed water, $\mathrm{mm}$ ),

$\sum P_{v}=$ sum of variable losses during the filling of $\mu$ $(\mathrm{mm})$,

$t_{1}=$ initial time when the precipitated volume is equal to the soil moisture content (min), and

$t_{2}=$ initial time when the precipitated volume is equal to the initial losses $P_{i}$ (min).

Note that the two last terms of the relationship in Equation 1 can be expressed as follows:

$$
\mu+\sum P_{v}=I\left(t_{2}-t_{1}\right)
$$

where:

$I=$ rainfall rate $(\mathrm{mm} / \mathrm{min})$,

$t_{2}=$ initial time when the initial loss $\left(P_{i}\right)$ is equal to the initial loss $\left(P_{i}, \mathrm{~min}\right)$, and

$t_{1}=$ initial time when the precipitated volume is

equal to the soil moisture content (min).

Obviously, from the time $t_{2}$, the losses become continuous, and in the case of a steady state, $P_{c}$ coincides with rainfall intensity $(I)$ when the runoff $(R)$ is neglected.

\subsection{Mathematical Formulations of the Drainage Porosity and of Variable Losses}

Based on the reservoir drainage principle, the drainage porosity of level 1 can be formulated. In terms of soil conservation, we can write:

$$
\frac{d h}{d t}=\left(Q_{a}-s \sqrt{2 g h(t)}\right) / S
$$

where:

$$
\begin{aligned}
\frac{d h}{d t} & =\text { filling speed }(\mathrm{m} / \mathrm{s}), \\
S & =\text { reservoir section }\left(\mathrm{m}^{2}\right), \\
Q_{a} & =\operatorname{inflow}\left(\mathrm{m}^{3} / \mathrm{s}\right), \\
h & =\text { filling height }(\mathrm{m}), \text { and } \\
s & =\text { leaking section }\left(\mathrm{m}^{2}\right) .
\end{aligned}
$$

Note that, for a rainfall of intensity $I, Q_{a}=S I$.

If we define

$$
I=\frac{s \sqrt{2 g h_{\infty}}}{S} \text { and } I=P_{c}
$$

then

$$
h_{\infty}=\mu
$$

so we have

$$
S I=s \sqrt{2 g h_{\infty}} \text { and } S P_{c}=s \sqrt{2 g \mu} .
$$

and from these two relationships we can deduce

$$
I / P_{c}=\sqrt{h_{\infty} / \mu} \text { or } h_{\infty}=\mu\left(I / P_{c}\right)^{2}
$$

and thus, the relationship (3) becomes:

$$
\frac{d h}{d t}=P_{c}\left(\sqrt{h_{\infty}}-\sqrt{h(t)}\right) / \sqrt{\mu}
$$

and by $u=\sqrt{h}$, we obtain the first-order differential equation

$$
2 u \frac{d u}{d t}=P_{c}\left(u_{\infty}-u\right) / \sqrt{\mu}
$$

By integrating between 0 and $\sqrt{\mu}$ for $u$ and between 0 and $\left(t_{2}-t_{1}\right)$ for $t$, we get the solution in terms of $\mu$ :

$$
\mu=-\frac{P_{c}\left(t_{2}-t_{1}\right)}{2 S\left(1+\operatorname{ILn}\left(1-P_{c} / I\right) / P_{c}\right)}
$$

This allows us to provide an expression of a blade water $(h)$ stored in the ground as a function of $t$ (measured from the time $t_{1}$ which is the time required to reach $H_{r}$ ):

$$
t=[\sqrt{h}+\alpha \operatorname{Ln}(1-\sqrt{h} / \alpha)] / k
$$

with

$$
\alpha=I \sqrt{\mu / P_{c}} \text { and } \alpha=-P_{c} \sqrt{\mu} / 2
$$

So, knowing the drainage porosity $\mu$, we can deduce variable losses from the relationship (2):

$$
\sum P v=\left(1+\frac{P_{c}}{2\left(1+\operatorname{ILn}\left(1-P_{c} / I\right) / P_{c}\right)}\right)\left(t_{2}-t_{1}\right)
$$

Based on a measure of $P_{c}$ that can be obtained via rain simulation, the relationship in Equation 8 allows to compute initial times and losses $P_{i}$, and this for any standard rainfall. 


\subsection{Determination of Initial Time}

In practice, the soil-as-reservoir analogy is imperfect, and, as shown in Figure 6 , runoff starts from the time $t_{T}$ while the reservoir is not entirely full. This defines a transient runoff prior to the completion of the steady state $t_{p}$. Note that $t_{T}$ is difficult to establish and subject to error since the start of runoff is generally not a discrete event. In addition, the time at which the onset of runoff will be observed depends locally on the state of the soil, of its structure, of its wettability and of its resistance to air pressure. Therefore, $t_{T}$ may vary.

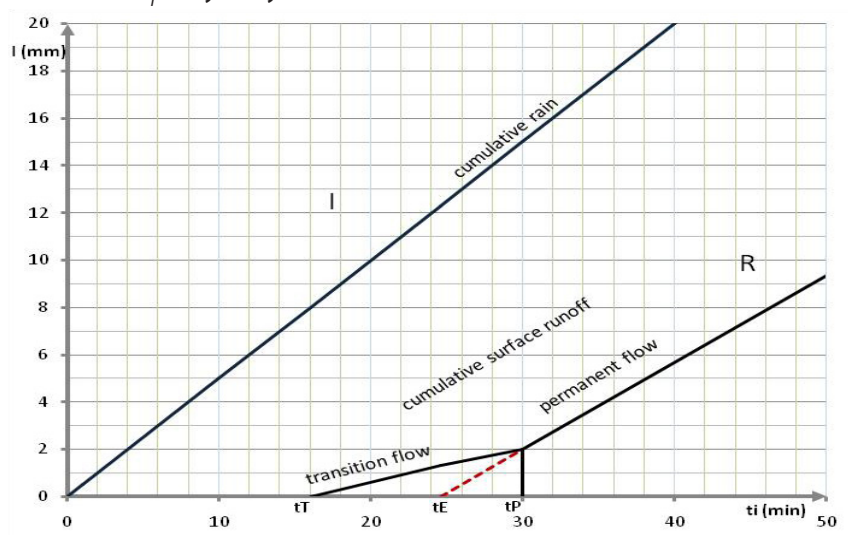

Figure 6 Estimation of the initial time.

The time at which the precipitated volume is equal to the initial losses $\left(P_{i}\right)$, that is, the time corresponding to the start of runoff, is therefore between the two times $t_{T}$ and $t_{P}$. This time is simply called the initial time $\left(t_{i}\right)$. Note that, in the steady state and in the case of a perfect soil, this time is equivalent to the initial time $\left(t_{E}\right)$ determined by the extension of the runoff curve to the horizontal axis.

Indeed, if time $t_{E}$ is not reached, the volumes of $H_{r}$ and $\mu$ cannot be completely filled. Beyond $t_{E^{\prime}}$ although there is still an infiltration deficit, the total amount of rainfall exceeds the volume of the initial losses. Thus for a given rainfall intensity, we see that both the initial time is exceeded and the volume of water located above the soil surface, which compensates volumes $\Delta \mu$ and $\Delta P_{v}$ (variable initial losses), is in deficit. This introduces the concept of initial losses and their variation versus the degree of soil saturation. In the following, the equivalent initial time $\left(t_{E}\right)$ will be considered as the initial time $\left(t_{i}\right)$.

\section{Soil Behaviours}

In this section, we present different cases of runoff curves obtained with an ORSTOM-type rain simulator, while commenting on them in terms of transport to the lower layer, distinguishing different cases.

\subsection{Findings}

Hereinafter, examples of the cumulated runoff curves are shown. These curves are derived from a series of simulations performed in winter as part of a study of the erosion of agricultural land in the area of Montreuil in northern France (Masson 1987; Masson 1992). A soil survey has established the soil map of the study area, and prior to each measurement the structure of the soil is analyzed. From the 28 studies carried out, we present only four that are characteristic of the runoff curves that can be derived. For each simulation, the accompanying graphs provide both observed and adjusted data. In our interpretation, transient and steady states were assumed to be line segments. Note that the uncertainties of in situ measurements in these examples are shown as soil anomolies, but they well illustrate the hydrodynamic characteristics of the soils on which the rainfall simulations are conducted.

\section{Superficial Crusts or Non-Porous Materials from the Sur- face}

To illustrate this first case (Figure 7), we continued the simulation performed on sandy silt soil based on alternate sand and clay layers. The above-ground parts of the phacelia growing on the plot were destroyed by frost, leaving the soil unprotected and iced. For this case, it must be noted that the non-permeable level 2 is in effect the surface.

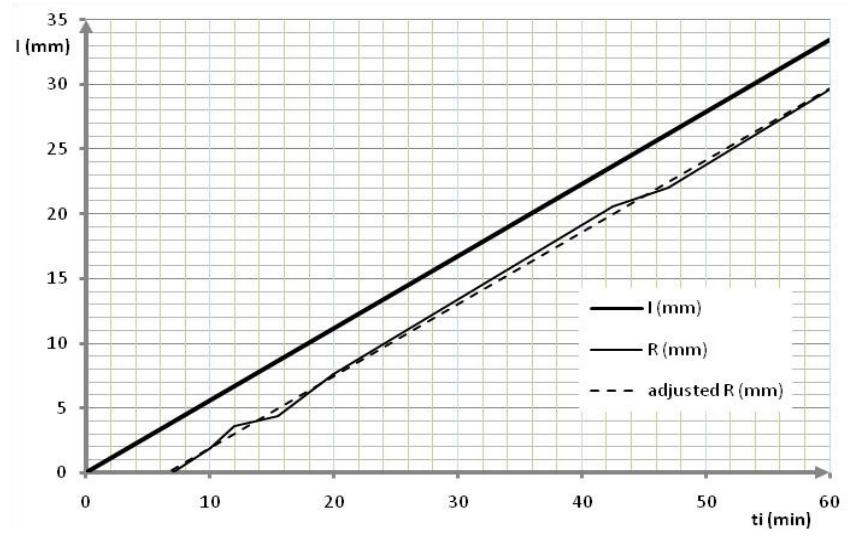

Figure 7 Case 1: Runoff on superficial crust (actual and interpreted data).

We observed a very small delay relative to the rainfall curve, and a very small amount of water is usually sufficient to wet the surface, which immediately becomes saturated ( $\mu=3.65 \mathrm{~mm}$, assuming that $H_{r}$ is reached at the beginning of the measure). The initial time $\left(t_{i}\right)$ is very brief ( $\left.6.56 \mathrm{~min}\right)$, and the cumulative runoff curve is parallel to the rainfall curve $\left(P_{c}=0\right)$ when runoff commences. Almost all of the rain is collected as runoff.

\section{Impermeable Level 2}

In this second case, a simulation was performed on soil that had been ploughed on the same day (soil of silty colluvium). Firstly, there is a delay and a transitional regime (Figure 8) that matches the phase of completely infiltrating the porous surface layer (level 1). At the change in the slope of the curve, a second curve nearly parallel to that of the rain $\left(P_{c}=0\right)$ is seen, which indicates the presence of an impermeable level 2 and all of the rain is 
routed as runoff. The time $t_{i}$ is significantly delayed ( $t=44.65 \mathrm{~min}$, $\mu=26.61 \mathrm{~mm}$, assuming that $H_{r}$ is reached at the beginning of the measurement).

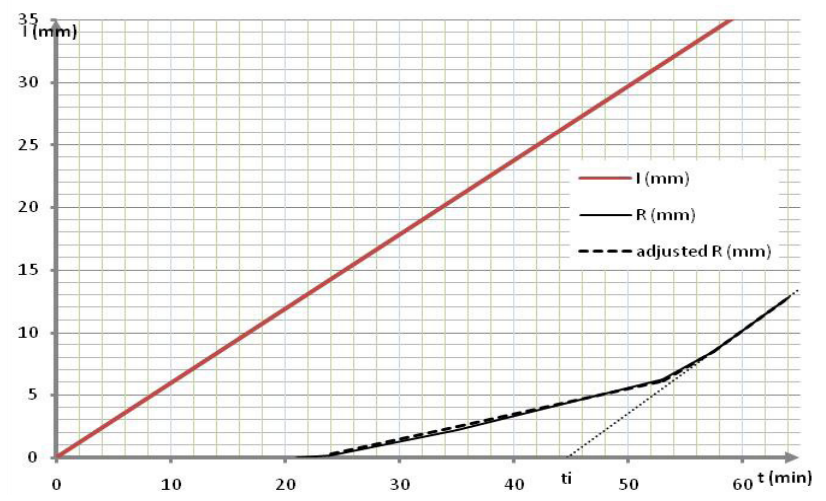

Figure 8 Case 2: Runoff on lower level.

\section{Semi-Permeable Level 2}

In this third case (Figure 9), we used measurements obtained from rain simulation on a soil covered with forage kale, stubble and regrowth (sandy silt soil based on alternate layers of sand and clay).

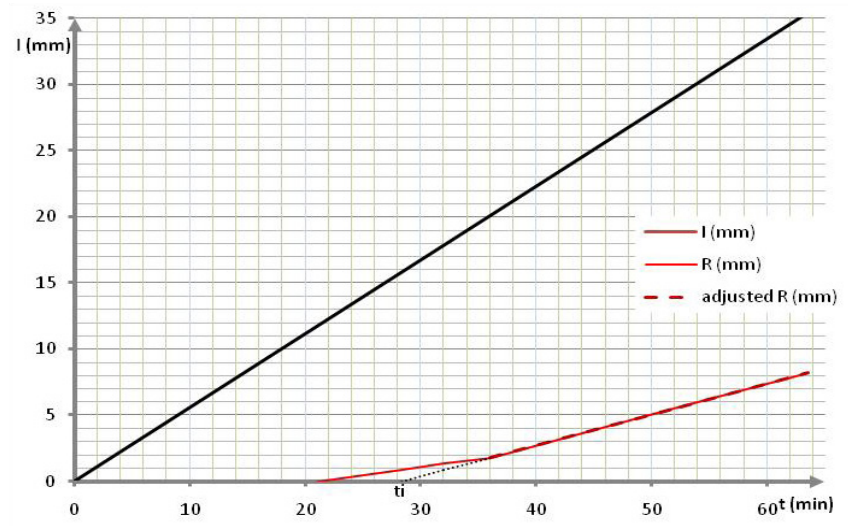

Figure 9 Case 3: Plough-pan or semi-permeable level (actual and interpreted data).

This figure shows a delay and a transient runoff regime, corresponding to the infiltration stage $(\mu=9.18 \mathrm{~mm})$ of the superficial porous layer (level 1). The initial time is $28.3 \mathrm{~min}$. At the change in slope, a second curve segment with a steeper slope than that of the rainfall curve indicates a less permeable level 2 , which is permeated by a fraction of the rain $\left(P_{c}=0.32 \mathrm{~mm} / \mathrm{min}\right)$.

\section{Natural Grass Surfaces or Old Meadows or Permeable}

\section{Material}

This fourth case is of a meadow (organic-rich loamy soil), shown in Figure 10.

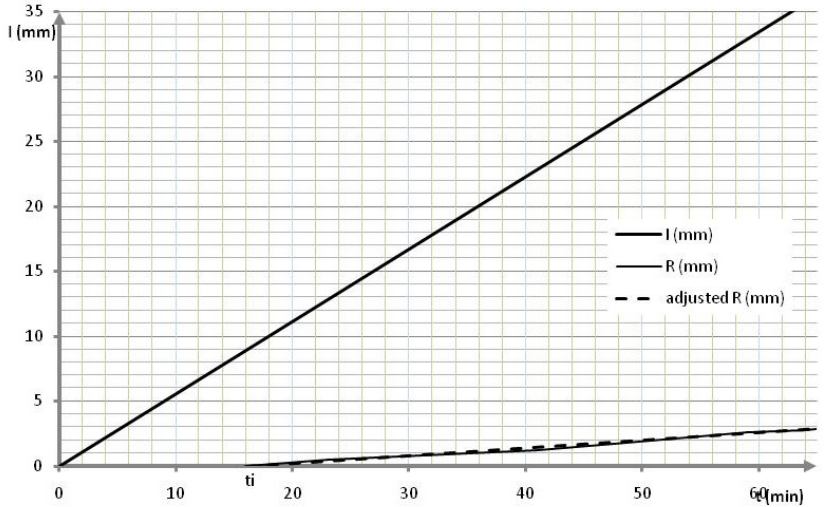

Figure 10 Case 4: Natural grass area and good structural organisation.

There is no transitional regime. Instead, a steady state with a very low slope, compared to that of the rainfall curve, is seen $\left(P_{c}=0.5 \mathrm{~mm} / \mathrm{min}\right)$. The analysis of the medium showed pores $(\mu=2.74 \mathrm{~mm})$ from the surface down to the deepest layers. The less permeable layer 2 allows a significant infiltration (shown by the shallow slope of the steady state). The high permeability of level 1 indicates the absence of a transient regime ( $t=16.63 \mathrm{~min}$ ).

\subsection{Other Possible Cases}

These simulations often involve gradual soil saturation and we can find other cases where the response of the soil is both extreme and obvious, such the saturation of the soil by shallow groundwater or a highly permeable soil that generates no runoff.

\section{Soil Saturation via Successive Steps}

Other situations may also be found. For example, consider the case of low permeability, or the case when the soil underlying level 2 gradually becomes less permeable, or the case when rainfall is too low to saturate the soil. To illustrate these cases, Figure 11 depicts a transient state (1) and two steady states ( 2 and 3 ).

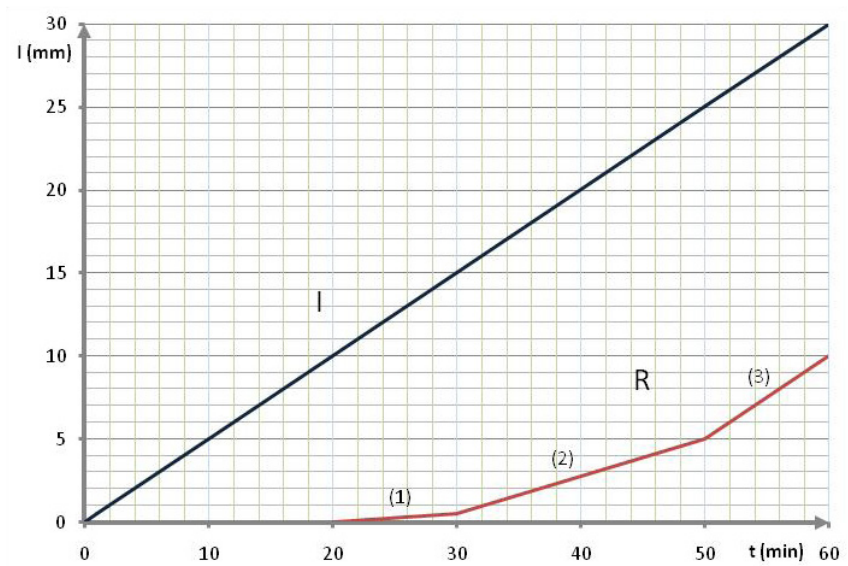

Figure 11 Appearance of several successive transitional and steady regimes. 
In the case of low rainfall, the runoff curves (segments 2 and 3) are not reached, and therefore need not be taken into account. Only the first state (segment 1) needs to be considered. In the case of a slightly permeable level underlying level 2, several successive steady states are possible because the lower level depth is less permeable than level 2. This is a case in which the model is repeated. We see the development of a new steady state (segment 3 in Figure 11). As an example, consider intermittent soil degradation such as an induration or an icing (Roose et al. 2012). In such a situation, for the same soil, it may be worthwhile to consider two distinct sets of measurements corresponding to two different soil conditions according to seasonal periods. For example, for the identification of watersheds, it may be necessary to take account of previous and actual rainfall events that could have changed the soil structure.

\section{Shallow Groundwater}

A shallow aquifer acts as an impermeable level 2 . This case is shown in Figure 12.

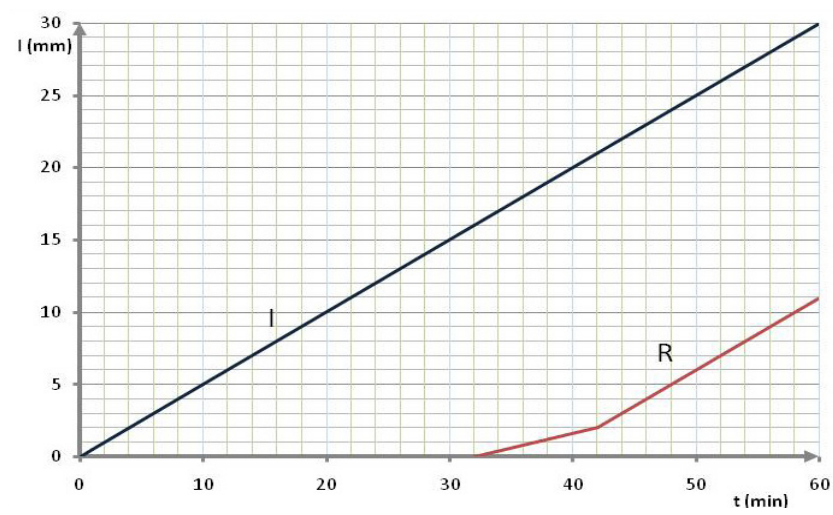

Figure 12 Cumulative runoff curve in the case of shallow groundwater.

Note that there is a transient state followed by a steady state with the same slope as the rainfall curve. Further, if the water (aquifer) is on the surface as groundwater, the entire rainfall will be treated as runoff.

\section{Soils with High Permeability}

Figure 13 shows the case of highly permeable soils with no runoff. The permeability of levels 1 and 2 allows water flow with a rate higher than that of the standard rainfall, which is shown by there being no runoff.

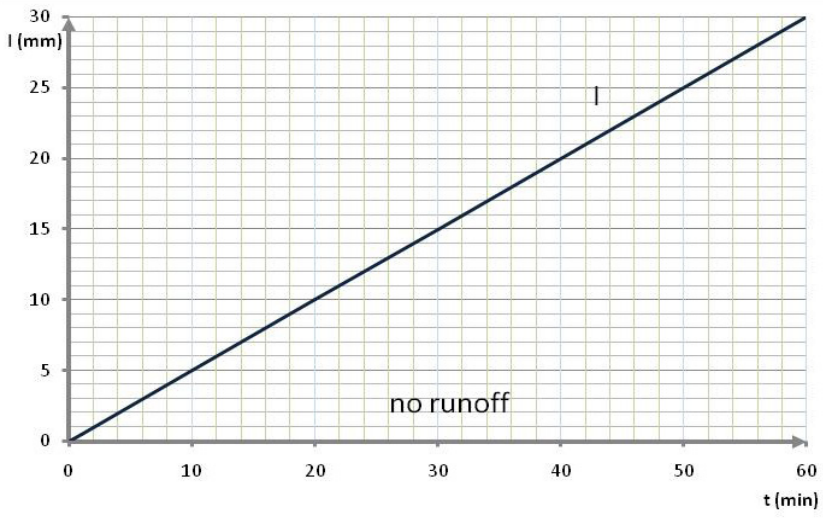

Figure 13 Case of no runoff from soils with high permeability.

\section{Application to Some Rainfall Templates}

Despite errors in measurements, and under the assumption that there is a standard rainfall, runoff curves allow us to determine, with a good approximation, the hydrodynamic characteristics of the soil. Thus these curves can also be used to compute the responses of soils subjected to different artificial rainfalls. In fact, if I becomes $l^{\prime}$, the initial time $\left(t_{2}^{\prime}-t^{\prime}\right)$ of Equation 6 can be obtained via the relationship:

$$
t_{2}^{\prime}-t_{1}^{\prime}=-\frac{2\left(1+I^{\prime} \operatorname{Ln}\left(P_{c} / I^{\prime}\right) / P_{c}\right)}{P_{c}} \mu
$$

Table 1 gathers the key parameters, namely $P C, \mu, t_{i}$ and $P_{i^{\prime}}$ for the simulated rainfall of $33 \mathrm{~mm} / \mathrm{h}$ and shows their predicted values for rainfall of $50 \mathrm{~mm} / \mathrm{h}$. In both cases, infiltration has previously occurred. In other words, the precipitation volumes only contribute to the drainage porosity and losses to the lower level (level 2).

Table 1 Estimation of initial times and losses for variable rainfalls.

\begin{tabular}{|c|c|c|c|c|c|c|}
\hline \multirow{4}{*}{ Case } & \multirow{4}{*}{$\begin{array}{c}P_{c} \\
(\mathrm{~mm} / \mathrm{min})\end{array}$} & \multirow{4}{*}{$\begin{array}{c}\mu \\
(\mathrm{mm})\end{array}$} & \multicolumn{2}{|c|}{$t_{2}-t_{1}(\min )$} & \multicolumn{2}{|c|}{$P_{i}(\mathrm{~mm})$} \\
\hline & & & Simulated rain & Planned rain & Simulated rain & Planned rain \\
\hline & & & $33.4 \mathrm{~mm} / \mathrm{h}$ & $50 \mathrm{~mm} / \mathrm{h}$ & $33.4 \mathrm{~mm} / \mathrm{h}$ & $50 \mathrm{~mm} / \mathrm{h}$ \\
\hline & & & $(0.557 \mathrm{~mm} / \mathrm{min})$ & $(0.833 \mathrm{~mm} / \mathrm{min})$ & $(0.557 \mathrm{~mm} / \mathrm{min})$ & $(0.833 \mathrm{~mm} / \mathrm{min})$ \\
\hline 1 & & 3.65 & 6.56 & 4.38 & 3.65 & 3.65 \\
\hline 2 & $\sim 0$ & 26.61 & 44.65 & 32.55 & 26.61 & 26.61 \\
\hline 3 & 0.322 & 9.18 & 28.26 & 15.11 & 15.76 & 12.59 \\
\hline 4 & 0.499 & 2.74 & 16.63 & 5.76 & 9.27 & 4.80 \\
\hline
\end{tabular}

To sum up, using the observed values of the simulation to predict the soil response to other rainfall events can lead to the identification of water volumes stored in the soil, which can enable us to manage rainfall events, and so protect ourselves. 


\section{Conclusions}

Water flow from the unsaturated zone of porous materials can be characterized from standard simulation experiments which measure constant rainfall runoff and estimate the initial time of the start of runoff. In addition, modeling the transport of water in soil that consists of two layers of different porosities allows us to estimate the drainage porosity.

In this paper, we have not considered the effects of water content. There may be a volume of retained water present in level 1. Moisture content is determined exogenously, and only free water that flows due to gravity has been measured in our simulation. For a different rainfall, we can determine the response of the same soil in terms of infiltrated and runoff volumes, provided that the receptor material remains unchanged. In other words, the aging or other transformations of the soil are not reflected in the calculated extrapolation of the soil response.

In our view a soil that has been battered by the impact of raindrops should be considered as a different soil, for which it is necessary to (re-)assess its hydrodynamic characteristics through rainfall simulation. At the landscape scale, our approach can estimate runoff volumes for a watershed after a rainfall. However, this requires simulations for representative cases actually encountered in terms of soil texture and soil cover.

The issue of fluctuation of the hydrodynamic characteristics of soils over time and space remains a challenge, even for mathematical models (Schwen et al. 2011). In our case, the more rain simulation measurements there are, the more this limitation will be overcome. This is an efficient approach that can be of great value for the computation of surface and subsurface flows in porous materials and in natural soils. The tracking of the transport of dissolved pollutants and assessing the risks of pollution to groundwaters or superficial environments is a potential large scale application for natural soils since the boundary effects of small samples could affect the results.

This work shows that runoff should be considered primarily in terms of groundwater hydraulics in non-saturated media. Likewise, in many cases, knowledge of soil capacity in terms of absorption rates allows us to manage the volumes of surface water flows. This opens up opportunities to prevent runoff, erosion, or floods in rural and urban areas. Another application would be to improve global understandings of surface runoffs in order to better replenish groundwater tables.

\section{Acknowledgments}

This work is based on data from the "Soil Mission" and Regional Direction of Water Management, Regional Department of the Agricultural and Forests of the North-Pas-de-Calais, France. In addition, this work conducted here has been financially supported by the European Regional Development Fund (ERDF) (Project No. 2013/01/22-PRESAGE 41732). This support is gratefully acknowledged.

\section{Declaration of Conflicting Interests}

The authors declare that there is no potential conflict of interest with respect to this research, authors, or the publication of this article.

\section{References}

Abudi, I., G. Carmi and P. Berliner. 2012. "Rainfall Simulator for Field Runoff Studies." Journal of Hydrology 454-455:76-81. https://doi.org/10.1016/j.jhydrol.2012.05.056.

Asseline, J. 1997. "Le simulateur de pluie en 1997 (Type ORSTOM, Asseline-Valentin)—Adaptations aux zones semi-arides et de montagne." Bulletin-Réseau Erosion, Journées du Réseau Erosion, Villeneuve de Berg, France, 1996/09/24-27: 272-81. http://www.documentation.ird.fr/hor/fdi:010011104.

Asseline, J. and C. Valentin. 1978. "Construction et mise au point d'un simulateur de pluie à aspersion." Cahier ORSTOM, Série Hydrologie, Paris 15 (4): 321-50.

Corradini, C., F. Melone and R. E. Smith. 1997. "A Unified Model for Infiltration and Redistribution During Complex Rainfall Patterns." Journal of Hydrology 192 (1-4): 104-24. https://doi.org10.1016/S0022-1694(96)03110-1.

Corradini, C., R. Morbidelli, A. Flammini and R. S. Govindaraju. 2011. "A Parameterized Model for Local Infiltration in Two-Layered Soils with a More Permeable Upper Layer." Journal of Hydrology 396 (3-4): 221-32. https://doi.org/10.1016/j.jhydrol.2010.11.010.

Deng, Z.-Q., J. L. M. P. De Lima and V. P. Singh. 2005. “Transport Rate-Based Model for Overland Flow and Solute Transport: Parameter Estimation and Process Simulation." Journal of Hydrology 315 (1-4): 220-35. https://doi.org/10.1016/j.jhydrol.2005.03.042.

Friedel, M. J. 2005. “Coupled Inverse Modeling of Vadose Zone Water, Heat, and Solute Transport: Calibration Constraints, Parameter Nonuniqueness, and Predictive Uncertainty." Journal of Hydrology 312 (1-4): 148-75. https://doi.org/10.1016/j.jhydrol.2005.02.013.

Furman, A. 2008. "Modeling Coupled Surface-Subsurface Flow Processes: A Review." Vadose Zone Journal 7 (2): 741-56. https://doi.org/10.2136/vzj2007.0065.

Gandolfi, C. and F. Savi. 2000. "A Mathematical Model for the Coupled Simulation of Surface Runoff and Infiltration." Journal of Agricultural Engineering Research 75 (1): 49-55. https://doi.org/10.1006/jaer.1999.0484.

Hamed, Y., J. Albergel, Y. Pépin, J. Asseline, S. Nasri, P. Zante, R. Berndtsson, M. El-Niazy and M. Balah. 2002. “Comparison Between Rainfall Simulator Erosion and Observed Reservoir Sedimentation in an Erosion-Sensitive Semiarid Catchment." Catena 50 (1): 1-16. https://doi.org/10.1016/S0341-8162(02)00089-9. 
Hingray, B., C. Picouet and A. Musy. 2009. Hydrologie 2, Une science pour l'ingénieur. Lausanne: Presses Polytechniques et Universitaires Romandes, EPFL Press.

Iserloh, T., et al. 2013. “European small portable rainfall simulators: A comparison of rainfall characteristics" Catena (2013), https://doi.org/10.1016/j.catena.2013.05.013

Köhne, J. M., T. Wöhling, V. Pot, P. Benoit, S. Leguédois, Y. Le Bissonnais and J. Šimunek. 2011. "Coupled Simulation of Surface Runoff and Soil Water Flow Using Multi-Objective Parameter Estimation." Journal of Hydrology 403 (1-2): 141-56. https://doi.org/10.1016/j.jhydrol.2011.04.001.

Lazrag, T., M. Kacem, P. Dubujet, J. Sghaier and A. Bellagi. 2012. "Détermination des propriétés hydrauliques non saturées à partir d'un essai de drainage gravitaire." XXème Rencontres Universitaires de Génie Civil, Chambéry, France, 6-8 Juin 2012.

Loveridge, M and A. Rahman. 2013. "Trend Analysis of Rainfall Losses Using an Event-Based Hydrological Model in Eastern NSW." In Proceedings, 20th International Congress on Modeling and Simulation (MODSIM2013), edited by J. Piantadosi, R. S. Anderssen and J. Boland. Canberra: Modelling and Simulation Society of Australia and New Zealand. http://www.mssanz.org.au/modsim2013/

Martin, C., M. Pohl, C. Alewell, C. Körner and C. Rixen. 2010. “InterRill Erosion at Disturbed Alpine Sites: Effects of Plant Functional Diversity and Vegetation Cover." Basic and Applied Ecology 11 (7): 619-26. https://doi.org/10.1016/j.baae.2010.04.006.

Martínez-Murillo, J. F., E. Nadal-Romero, D. Regüés, A. Cerdà and J. Poesen. 2013. "Soil Erosion and Hydrology of the Western Mediterranean Badlands Throughout Rainfall Simulation Experiments: A Review." Catena 106:101-12. https://doi.org/10.1016/j.catena.2012.06.001.

Masson, F. X. 1987. "L'érosion des terres agricoles de la région Nord-Pas-de-Calais." Hommes et Terres du Nord 3:139-45.

Masson, F. X. 1992. "Gestion des sols de la Région du Nord (France). Relation sols et formations superficielles. Proposition d'une démarche générale." PhD Thesis, University of Lille 1-Sciences and Technologies, France.

Mertens, J., H. Madsen, L. Feyen, D. Jacques and J. Feyen. 2004. "Including Prior Information in the Estimation of Effective Soil Parameters in Unsaturated Zone Modeling." Journal of Hydrology 294 (4): 251-269. https://doi.org/10.1016/j.jhydrol.2004.02.011.

Neave, M. and S. Rayburg. 2007. “A Field Investigation into the Effects of Progressive Rainfall-Induced Soil Seal and Crust Development on Runoff and Erosion Rates: The Impact of Surface Cover." Geomorphology Journal 87 (4): 378-90 https://doi.org/10.1016/j.geomorph.2006.10.007.
Panday, S. and P. S. Huyakorn. 2004. "A Fully Coupled Physically-Based Spatially Distributed Model for Evaluating Surface-Subsurface Flow." Advanced Water Resources 27 (4): 361-82 https://doi.org/10.1016/j.advwatres.2004.02.016.

Perez-Latorre, F. J., L. De Castro and A. Delgado. 2010. "A Comparison of Two Variable Intensity Rainfall Simulators for Runoff Studies." Soil \& Tillage Research 107 (1): 11-6. https://doi.org/10.1016/j.still.2009.12.009.

Roose, E., M. Sabir, M. Arabi, B. Morsli and M. Mazour. 2012. "Soixante années de recherche en coopération sur l'érosion hydrique et la lutte antiérosive au Maghreb." Physio-Géo 6: 43-69. https://doi.org/10.4000/physio-geo.2319.

Salles, C. and J. Poesen 2000. "Rain Properties Controlling Soil Splash Detachment." Hydrological Processes 14 (2): 271-82. https://doi.org/10.1002/(SICI)10991085(20000215)14:2<271:AID-HYP925>3.0.CO;2-J.

Schwen, A., G. Bodner and W. Loiskand. 2011. "Time-Variable Soil Hydraulic Properties in Near-Surface Soil Water Simulations for Different Tillage Methods." Agricultural Water Management 99 (1): 42-50. https://doi.org/10.1016/j.agwat.2011.07.020.

Simunek, J., N. J. Jarvis, M. T. Van Genuchten and A. Gärdenäs. 2003. “Review and Comparison of Models for Describing Non-Equilibrium and Preferential Flow and Transport in the Vadose Zone." Journal of Hydrology 272 (1-4): 14-35. https://doi.org/10.1016/S0022-1694(02)00252-4.

Singh, V. P. and D. A. Woolhiser. 2002. "Mathematical Modeling of Watershed Hydrology". Journal of Hydrologic Engineering 7 (4): 270-92. https://doi.org/10.1061/(ASCE)1084-0699 (2002)7:4(270).

Vogel, H. J., I. Cousin, O. Ippisch and P. Bastian. 2006. “The Dominant Role of Structure for Solute Transport in Soil: Experimental Evidence and Modeling of Structure and Transport in a Field Experiment." Hydrology and Earth System Sciences 10:495-506. https://doi.org/10.5194/hess-10-495-2006.

Wöhling, T. and G. H. Schmitz. 2007. “Physically Based Coupled Model for Simulating 1D Surface-2D Subsurface Flow and Plant Water Uptake in Irrigation Furrows: II. Model Test and Evaluation. Journal of Irrigation and Drainage Engineering 133 (6): 548-58. https://doi.org/10.1061/(ASCE)0733-9437(2007)133:6(548). 